\title{
Effect of Stored Tiger Nut Oil Cultivars on the quality Properties of Fried Plantain Chips
}

\author{
Nina G.C $\mathbf{1}$, Ukeyima $\mathrm{M}^{2}$, and Ogori A.F ${ }^{3}$ \\ ${ }^{1}$ Department of Food Science and Technology, Federal University of Agriculture, Makurdi, Benue State, Nigeria. Email: \\ ninakelechiolo22@gmail.com \\ ${ }^{2,3}$ Department of Home Sciences, Faculty of Agriculture, Federal University, Gashua, P.M.B.1005 Gashua, Yobe State, Nigeria. \\ *Corresponding Author: Ogori Akama Friday, Department of Home Sciences, Faculty of Agriculture, Federal University, Gashua, P.M.B.1005 \\ Gashua, Yobe State, Nigeria. Email: ogorifaraday@gmail.com \\ Received date: September 18, 2020; Accepted date: October 09, 2020; Published date: October 18, 2020 \\ Citation: Nina G.C, Ukeyima M, and Ogori A.F, Effect of Stored Tiger Nut Oil Cultivars on the quality Properties of Fried Plantain Chips J. \\ Nutrition and Food Processing 3(3); DOI: 10.31579/2637-8914/029
}

Copyright: ( ) 2020, Ogori Akama Friday, This is an open access article distributed under the Creative Commons Attribution License, which permits unrestricted use, distribution, and reproduction in any medium, provided the original work is properly cited.

\begin{abstract}
Studies on plantain chips fried with varietal stored tiger nut oil were studied. Three different tiger nut cultivars were sou rced from Benue state and their oil extracted using hexane in an extractor. The stored oils were used to fry plantain chips after potatoes slicing and oil quality and stability analyzed. The moisture values of the chips from 0 week to week 12 for sample (A) ranged between 2.09-2.41 and 2.08-3.48 for samples (B) and (C) respectively.The thiobarbituric acid value from zero week - week12 for sample B O ranged between 0.19-0.21 malon $\mathrm{mg}$, sample BO ranged between 0.27-0.36 malon mg, while sample C ranged between $0.23-0.24$ malom mg. The appearance, aroma, taste, texture and overall acceptability of the chips ranged between 6.25-7.40, 6.20-6.55, 6.30-6.45, 6.20-6.55 and 6.15-6.55 respectively. Sample A and CKO (control) was most preferred in terms of appearance, aroma, taste, texture (crispness) and overall acceptability while sample A and C was least preferred. The sensory scores of the plantain chips fried with the oil were high for taste and aroma. During the storage, moisture values and thiobarbituric acid values of the chips were within the limits as recommended by CODEX Alimentarius.
\end{abstract}

Keywords: tiger nut; oil, storage; plantain chips frying; sensory quality

\section{Introduction}

Tiger nut (Cyperus esculentum) is a grass-like plant with spheroid tubers, pale yellow cream kernel surrounded by a fibrous sheath Nina et al (2019). It is also known as yellow nut sedge. Tiger nuts are edible, sweet, nutty, flavored tubers which contain nutrients (FAO, 2000). There are mainly three varieties namely: black, brown and yellow, and only yellow and brown are readily available in the Nigerian markets. Nina et al 2019. Plantain chips are the most popular plantain products in Nigeria. They are prepared by slicing ripened plantain with into diameter, $2 \mathrm{~mm}$ and put in a vegetable oil at the temperature between frying temperature below flash point for 5 minutes. The plantain chips prepared in this way are packed in plastics or in polyethylene bags and stored at 30+/-2 degrees $\mathrm{C}$ for 2 3 months at room temperature respectively (Akubor and Adejo, 2000). However, the shelf life of plantain chips are reduced when exposed to light and air. The poor shelf life of plantain chips is due to lipid oxidation occasioned by the heat, oxygen, light, heavy metals, pigments, alkaline condition and degrees of unsaturation are catalyst in this process producing off flavors and odors called rancidity. This work seeks to investigate the quality of plantain chips when tiger nut -oil is used as a frying medium.

\section{Materials and Methods}

\section{Procurement of Raw Materials}

Brown and yellow tiger nuts were purchased from North bank market Makurdi, while the black tiger nut was purchased from Vande Ikya market, all in Benue State, Nigeria. They were taken to the Department of
Agronomy, Federal University of Agriculture, Makurdi for identification. The plantain chips were bought from North bank market, in Makurdi.

\section{Extraction of tiger nut oil}

Tiger nut oil was extracted from the resulting flour using $\mathrm{n}$ hexane a nonpolar solvent) according to AOAC, (2012) as presented in figure 20 . Flour samples (1050g sample A, 1050g for sample B and 1050g for sample C) were used for extraction using a soxhlet extractor. The lipid was extracted for $5 \mathrm{hr}$. With a $500 \mathrm{ml}$ volumetric flask containing the solvent, which was heated with an electric heater at $70^{\circ} \mathrm{C}$. Oil/solvent extracts were evaporated off using rotary evaporator and later oven dried at $105^{\circ} \mathrm{C}$ for $1 \mathrm{hr}$. and stored in bottles to be analyzed later.

\section{Determination of moisture value}

Moisture content of tiger nut oil was determined by the AOAC Official method (2000). Into dried, and weighed moisture dish was added $5 \mathrm{~g}$ tiger nut oil. This was heated in an oven Memmert, Germany at $105^{\circ} \mathrm{C}$ for 1 hour, cooled in a desiccator containing phosphorus peroxide and weighed. This was repeated until a constant weight obtained.

\section{Methods}

\section{Determination of moisture value}

Moisture content of tiger nut oil was determined by the AOAC Official method (2000). Into dried, and weighed moisture dish was added $5 \mathrm{~g}$ tiger nut oil. This was heated in an oven 
Memmert, Germany at $105^{\circ} \mathrm{C}$ for 1 hour, cooled in a desiccator containing phosphorus peroxide and weighed. This was repeated until a constant weight obtained.

Where,

$$
\begin{aligned}
\text { Moisture }=\% \text { Moisture } & =\frac{\text { Loss in mass on drying }}{\text { Weight of test sample }} \times 100 \\
& =\frac{M s-M h}{M s-M t}
\end{aligned}
$$

Ms $=$ Weight of moisture dish + Sample $(\mathrm{g})$

$\mathrm{Mh}=$ Weight of moisture dish + sample after heating $(\mathrm{g})$

$\mathrm{Mt}=$ Weight of Tare/moisture dish $(\mathrm{g})$

\section{Thiobarbituric acid value}

Thiobarbituric acid value was determined according to the method described by

Benchamaporn et al . (2009). A fifty (50) milligram sample was accurately weighed into a

Twenty-five milliliter volumetric flask and dissolved in a small volume of 1-butanol and made up to volume with 1-butanol. Then $0.5 \mathrm{~mL}$ of the sample solution was transferred to a dry test tube and $5 \mathrm{~mL}$ of TBA reagent solution $(0.2883 \mathrm{G} / 100 \mathrm{ml}$ of $90 \%$ glacial acetic acid) added. The test tube was closed with a ground-glass stopper, mixed thoroughly and placed in a thermostatic bath at $95^{\circ} \mathrm{C}$. After $120 \mathrm{~min}$, the test tube was removed from the thermostatic bath and cooled under running tap water for about $10 \mathrm{~min}$ until it reaches room temperature. The absorbance of the reaction solution was then measured at 530nm using distilled water in the reference cuvette. A reagent blank was also prepared and read. The result was calculated using the equation below:

$$
\mathrm{TBAR} \text { value }=\text { TBAR value }=\frac{[50 \times(A-B)]}{m}
$$

Where: $\quad \mathrm{A}=$ absorbance of the test solution, $\mathrm{B}=$ absorbance of the reagent blank, $\mathrm{m}=$ the weight $(\mathrm{g})$ of the test sample.

\section{Storage Studies}

Plantain chips fried with tiger oil was packaged in a high density polyethylene and stored in a desiccator at room temperature $\left(28^{\circ} \mathrm{C}\right)$ for a period of three months (12 weeks). The samples were analyzed at two weeks interval to evaluate thiobarbutirc acid (TBA), and moisture content.

\section{Sensory Evaluation}

Unripe Plantain chips samples were fried with tiger nut oil and refined groundnut oil .The chips were evaluated on the basis of taste, flavor, appearance, texture and overall acceptability. Twenty (20) panelists were selected among the staff and students of Department of Food Science and Technology, Federal University of Agriculture, Makurdi. The plantain chips were evaluated using a nine point hedonic scale for sensory scoring (Iwe, 2002). Samples were served in a randomized manner on a tray

\section{Statistical Analysis}

All experiment was conducted in duplicate and subjected to analysis of variance (ANOVA) using statistical package of Social Sciences (SPSS) version 20.0. Means separation was done using Duncan Multiple Range Test and significant difference was established at $\mathrm{p}<0.05$.

\section{Effect of Storage on the Moisture Content (\%) of Plantain Chips Fried with Tiger oil cultivars}

There was a significant $(\mathrm{p}<0.05)$ difference between the samples as storage time increased but the moisture content increased and decreased as the storage time increased. It was also in agreement with the acceptable limit for moisture content. The moisture content of food gives an

\begin{tabular}{|c|c|c|c|c|c|c|c|}
\hline \multicolumn{8}{|c|}{ Storage time (weeks) } \\
\hline Sample & 0 & 2 & 4 & 6 & 8 & 10 & 12 \\
\hline $\mathbf{A}$ & $2.09^{\mathrm{b}} \pm 0.02$ & $2.19^{c} \pm 0.07$ & $2.32^{\mathrm{b}} \pm 0.00$ & $2.42^{\mathrm{b}} \pm 0.01$ & $2.41^{\mathrm{b}} \pm 0.01$ & $2.33^{\mathrm{b}} \pm 0.01$ & $2.35^{\mathrm{b}} \pm 0.02$ \\
\hline B & $2.80^{\mathrm{a}} \pm 0.04$ & $2.35^{\mathrm{b}} \pm 0.05$ & $2.11^{\mathrm{c}} \pm 0.01$ & $2.14^{\mathrm{c}} \pm 0.00$ & $2.14^{\mathrm{c}} \pm 0.00$ & $2.09^{\mathrm{c}} \pm 0.01$ & $2.09^{c} \pm 0.04$ \\
\hline $\mathbf{C}$ & $2.08^{\mathrm{c}} \pm 0.04$ & $3.48 \pm 0.00$ & $3.04^{\mathrm{a}} \pm 0.05$ & $3.01^{\mathrm{a}} \pm 0.00$ & $3.02^{\mathrm{a}} \pm 0.01$ & $3.02^{\mathrm{a}} \pm 0.00$ & $3.02^{\mathrm{a}} \pm 0.00$ \\
\hline
\end{tabular}
indication of its shelf-life and nutritive value, hence low moisture content is a requirement for long storage life (Okene and Evbuomwan 2014).

Values are Means \pm Standard deviation of triplicate determinations. Means values down the column followed with different superscripts are significantly $(\mathrm{p}<0.05)$ different.

Keys:

Superscripts: Separation of means for samples

Sample A = sweet potatoes in stored Black tiger nut oil

$\mathrm{B}=$ sweet potatoes in stored Brown tiger nut oil

$\mathrm{C}=$ sweet potatoes in stored Yellow tiger nut oil Table 1: Effect of Storage on the Moisture Content (\%) of Plantain Chips Fried with Tiger oil cultivars

\section{Effect of Storage on the Thiobarbituric Acid (malon $/ \mathrm{mg}$ ) of the Plantain Chips Fried with Tiger Nut oil cultivars.}

Result of the effect of storage of tiger oil on thiobarbituric acid values of the chips fried with tiger nut oils is shown in table 3. The thiobarbituric acid values of the chips from 0 to week 12 for black tiger nut oil ranged between $0.19-0.21$ malon $\mathrm{mg}$, Brown tiger nut oil sample ranged between $0.27-0.36 \mathrm{malon} / \mathrm{mg}$, while yellow tiger nut oil sample ranged between 0.23-0.24 malom/ mg. There was unsteady increase and decreased in thiobarbituic acid values in chips samples in Black oil and Brown oil samples respectively, while Yellow sample increased during the storage period.

There was also a significant $(\mathrm{p}<0.05)$ difference between the chips samples as storage time increased. The thiobarbituric acid of the chips increased as the storage time increased. According to Valde's et al. (2005), thiobarbituric value usually is more sensitive at the early stages of oxidation. Unsaturated fatty acids particularly linolenic acid is responsible for developing the colour clearly with thiobarbituric and the major compound formed such as malondialdehydes. 


\begin{tabular}{|c|l|l|l|l|l|l|l|}
\hline \multicolumn{8}{|c|}{ Storage time (weeks) } \\
\hline Samplesle & 0 & 2 & 4 & 6 & 8 & 10 & 12 \\
\hline A & $0.19^{\mathrm{c}} \pm 0.00$ & $0.21^{\mathrm{b}} \pm 0.01$ & $0.21^{\mathrm{b}} \pm 0.00$ & $0.20^{\mathrm{c}} \pm 0.00$ & $0.21^{\mathrm{c}} \pm 0.00$ & $0.21^{\mathrm{b}} \pm 0.01$ & $0.21^{\mathrm{b}} \pm 0.01$ \\
\hline B & $0.27^{\mathrm{a}} \pm 0.01$ & $0.28^{\mathrm{a}} \pm 0.02$ & $0.28^{\mathrm{a}} \pm 0.01$ & $0.36^{\mathrm{a}} \pm 0.00$ & $0.35^{\mathrm{a}} \pm 0.00$ & $0.35^{\mathrm{a}} \pm 0.00$ & $0.35^{\mathrm{a}} \pm 0.00$ \\
\hline C & $0.23^{\mathrm{b}} \pm 0.01$ & $0.23^{\mathrm{b}} \pm 0.00$ & $0.23^{\mathrm{b}} \pm 0.00$ & $0.23^{\mathrm{b}} \pm 0.00$ & $0.23^{\mathrm{b}} \pm 0.00$ & $0.24^{\mathrm{b}} \pm 0.00$ & $0.24^{\mathrm{b}} \pm 0.00$ \\
\hline
\end{tabular}

Values are Means \pm standard deviation of triplicate determinations. Means values down the column followed with different superscripts are significantly $(\mathrm{p}<0.05)$ different.

Keys:

Superscripts: Separation of means for samples

Sample $A=$ sweet potatoes in stored Black tiger nut oil

$\mathrm{B}=$ sweet potatoes in stored Brown tiger nut oil

$\mathrm{C}=$ sweet potatoes in stored Yellow tiger nut oil

Table 2: Effect of Storage on the Thiobarbituric Acid (malon/mg) of the Plantain Chips Fried with Tiger Nut Oil cultivars

Effect of storage on the moisture content of plantain chips fried with tiger nut oil from different cultivars

There was a significant $(\mathrm{p}<0.05)$ difference between the samples as storage time increased According to (EAS, 2010) maximum moisture level for chips should not exceed $4.7 \%$ (EAS, 2010). The moisture content of chips obtained in this study did not exceed the maximum limit, chips can be stored up to 5 months. Moisture content reflects shelf life of food materials, such as the rate of microbial spoilage of food products.

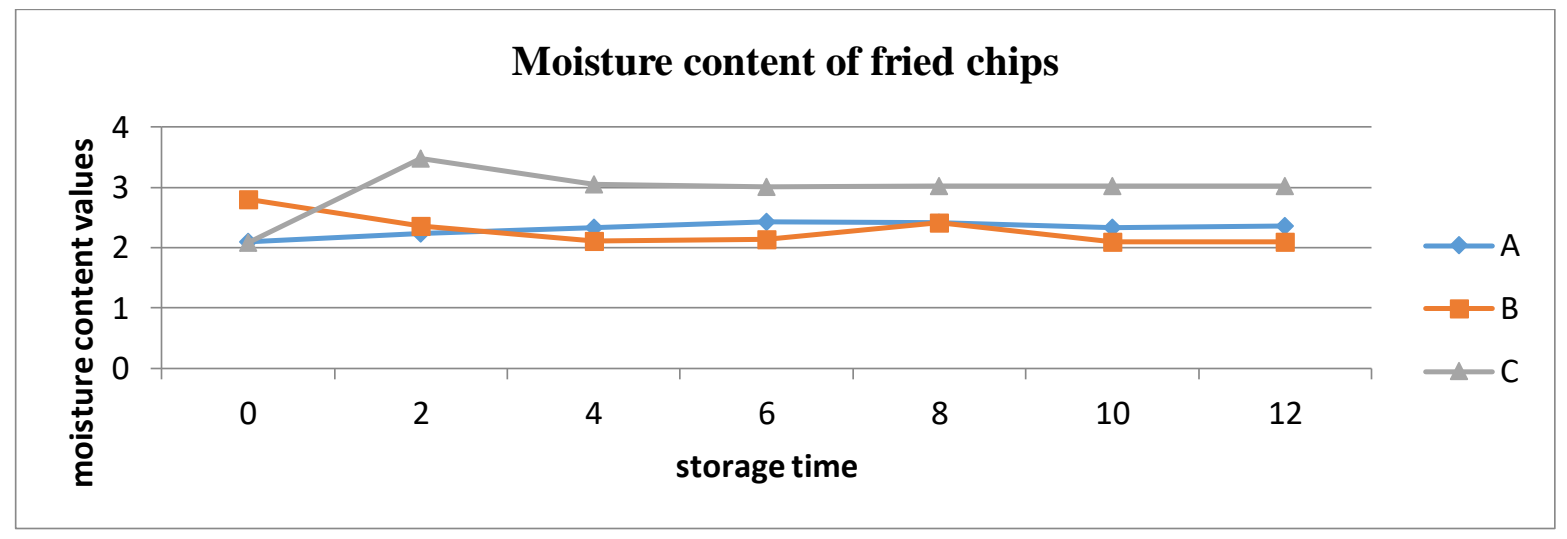

Key:

$$
\begin{aligned}
& A=\text { sweet potatoes in stored Black tiger nut oil } \\
& B=\text { sweet potatoes in stored Brown tiger nut oil } \\
& C=\text { sweet potatoes in stored Yellow tiger nut oil }
\end{aligned}
$$

Figure 1: moisture content of stored fried chips

\section{Sensory Properties of Plantain chips Fried with Tiger Nut Oil from Different}

\section{Cultivars}

Results of the sensory scores of plantain chips fried with oils from different cultivars of tiger nuts and refined groundnut king oil (sample D as control) (Table 3) showed existing difference between them and the control. However, no significantly $(\mathrm{P}>0.05)$ different from their controls for most of the parameters evaluated. There was significant $(\mathrm{p}<0.05)$ difference in the appearance, aroma, texture, flavor and general acceptability of the chips fried with oil from sample A (black cultivar) and the refined oil (sample D). This indicates that tiger nut oil has good nutritive value and good for cooking hence, appearance is an important attribute in food choice and acceptance (Muhimbula et al., 2011).
Samples A and D were preferred in terms of appearance, aroma, flavor, texture and general acceptability.

Based on the aroma, there was no significant $(p>0.05)$ difference in all the samples. The aroma is an integral part of taste and general acceptance of the food before it is put in the mouth, hence test acceptability of formulated foods (Muhimbula et al., 2011). The tastes in all the samples were not significantly $(\mathrm{p}>0.05)$ difference, based on the preference of the panelists. Taste is an important parameter when evaluating the sensory attribute of food .There was no significant $(p>0.05)$ difference in the texture of samples A (black cultivar) and B (brown cultivar) while there were no significant $(\mathrm{p}>0.05)$ difference in samples D (control) and C (yellow cultivar). This also could be as a result of difference in cultivar. The overall acceptability was significantly $(\mathrm{p}<0.05)$ different in all the samples. Samples A and D were preferred followed by sample C while sample B was least preferred. 


\begin{tabular}{|l|l|l|l|l|l|}
\hline Samples & Appearance & Aroma & Taste & Texture & $\begin{array}{c}\text { Overall } \\
\text { Acceptability }\end{array}$ \\
\hline D & $6.65^{\mathrm{b}} \pm 0.59$ & $6.50^{\mathrm{a}} \pm 0.51$ & $6.40^{\mathrm{a}} \pm 0.59$ & $6.55^{\mathrm{a}} \pm 0.51$ & $6.55^{\mathrm{a}} \pm 0.51$ \\
\hline A & $7.40^{\mathrm{a}} \pm 0.50$ & $6.25^{\mathrm{a}} \pm 0.44$ & $6.40^{\mathrm{a}} \pm 0.50$ & $6.20^{\mathrm{b}} \pm 0.52$ & $6.30^{\mathrm{a}} \pm 0.57$ \\
\hline B & $6.25^{\mathrm{b}} \pm 0.64$ & $6.55^{\mathrm{a}} \pm 0.76$ & $6.45^{\mathrm{a}} \pm 0.51$ & $6.20^{\mathrm{b}} \pm 0.41$ & $6.15^{\mathrm{b}} . \pm 0.37$ \\
\hline C & $6.35^{\mathrm{b}} \pm 0.75$ & $6.20^{\mathrm{a}} \pm 0.41$ & $6.30^{\mathrm{a}} \pm 0.47$ & $6.55^{\mathrm{a}} \pm 0.51$ & $6.20^{\mathrm{b}} \pm 0.41$ \\
\hline
\end{tabular}

Values are Means \pm standard deviation of duplicate determinations. Mean values down the column followed by different superscripts are significantly $(\mathrm{p}<0.05)$ different.

Key:

$$
\begin{aligned}
& A=\text { sweet potatoes in stored Black tiger nut oil } \\
& B=\text { sweet potatoes in stored Brown tiger nut oil } \\
& C=\text { sweet potatoes in stored Yellow tiger nut oil }
\end{aligned}
$$
Table 3: Sensory Scores of Plantain Chips Fried with Crude cultivars of Tiger nut oil cultivars

\section{Conclusion}

The effect of storage on some of the quality parameters analyzed on the chips after frying showed that there were changes during storage but changes did not exceed maximum limits of CODEX Alimentarius. The sensory properties of the oil fried with plantain chips showed that the oil could be used as cooking and frying oils. It has good taste and aroma. Indicating that tiger nut oil is a good oil and can be important in providing food security, enhancing livelihoods, improving nutritional status and social wellbeing of vulnerable groups.

\section{References}

1. Adejuyitan, J. A, Otunola, E. T., Akande, E. A., Bolarinwa, I. F. and Oladokun, F. M. (2009).

2. Some physicochemical properties of flour obtained from fermentation of tiger nut (Cyperus esculentus) sourced from a market in Ogbomoso, Nigeria. African Journal of Food Science. Vol 3(2) pp.051-055, February, 2009.

3. Alam, M. S., Islam M. F, Begum, M. A, Sarkar, Banu M. S (2001).Abundance of fungal flora in relation to moisture and storage and storage period in different types of poultry feed ingredients.Pak. J.biol.Sci, 4: 1194-1197.

4. Akubor P. I. and Adeejo E. E. (2000). Physiochemical, microbiological and sensory change in stored plantain chips. Plants foods human nutrition volume; 55 issue (2); pg. 139-146.

5. AOAC. (2010). Official Methods of Analysis: Association of Official analytical Chemists, Washington, DC. USA.

6. AOAC (2012). Official Methods of Analysis. 18th Ed. American Association of Analytical Chemists, Inc., Washington.

7. Bamishaiye E. I and Bamishaiye O.M. (2011). Tiger nut: as a plant, its derivatives and benefits. African journal of Food Agriculture, Nutrition and Development, Vol. 11 No 5.ISSN 1684 5378. Benchamaporn, P., Duangkhae, K. and Sophon, B. (2009). Effect of Addition of Antioxidants on the Oxidative Stability of
Refined Bleached and Deodorized Palm Olein. Kasetsart Journal of Natural Science, 43: 370 - 377.

8. EAS, (2010). Potato crisps specifications. 1st Edn. East African Standards, USA. Ezebor F, Igwe C.C,

9. FAO/WHO, (2000). Human vitamin and mineral requirements FAO/WHO expert consultation on human vitamin and mineral requirement. Pp $1-286$.

10. Muhimbula, H. E., Issa-Zacharia, A. and Kinabo, J. (2011). Formulation and sensory evaluation of complementary foods from local, cheap and readily available cereals and legumes in Iringa, Tazania. African Journal of Food Science, 5 (1): 26 - 31.

11. Shaker, M. A., Ahmed, M. Gaafar, Amany M. Basuny and Shereen L. Nassef (2009). Chufa Tubers (Cyperus esculentus L.): As a New Source World Applied Sciences Journal. 7(2): 151-156.

12. Ezebor, F., Igwe, C. C, Owolabi F. A. T, and Okoh S.O. (2005). Comparison of the PhysicChemicalCharacteristics, Oxidative and Hydrolytic Stabilities of Oil and Fat of Cyperus Esculentus L. And Butyrospermum Parkii (Shea Nut) From Middle-Belt States of Nigeria. Nigerian Food Journal 23: 33-39.

13. Tchango, J., Tchango, A. B, Achard, R. Escalant, J. V. and Ngalani, J. A. (1999). Plantain: Post Harvest Operations. FAO, Center De Recherches Regionales Sur Bananiers Et Plantains.Cameroun Crbp. Edited By Agsi/Fao:Danilo Mejia And Beverly Levels, 1-58 Pp.

14. Okene, E. O. and Evbuomwan, B. O. (2014). Solvent Extraction and Characterization of Oil from Coconut Seed using Alternative Solvents. International Journal of Engineering and Technical Research (Ijetr) 2(12), 135-138

15. Iwe, M. O (2002). Current Trends in Sensory Evaluation of Foods. Region Communication Services Ltd, Enugu. 46 - 47.

16. Valde's, F. Adolfo, B. Garcia, Ana (2006). A study of the evolution of the physicochemical and structural characteristics of olive and sunflower oils after heating at frying temperatures. 